\title{
AKUNTAN DAN ERA KETERBUKAAN ARUS LALU LINTAS JASA
}

\author{
Vidia G ati \\ D osen FEBI UIN SA Surabaya | vidiagatira@ gmail.com
}

\begin{abstract}
Profesi akuntan adalah salah satu profesi yang mendapatkan sertifikasi dari negara negara ASEAN berdasarkan Mutual Recognition Agreement (MRA sehingga nantinya akan memudahkan lintas profesi diantara Negara tersebut. Adanya gap antara jumlah akuntan yang tersedia dan yang dibutuhkan akan menimbulkan persoalan yaitu serbuan tenaga kerja asing di masa arus lalu lintas jasa benar benar terbuka. Ikatan Akuntan Indonesia sudah melakukan berbagai aktifitas untuk mempersiapkan masa tersebut, namun hendaknya perhitungan realistis perlu dikedepankan mengingat struktur sumber daya manusia di Indonesia didominasi oleh low skilled labour sehingga opsi menunda pemberlakuannya mungkin dapat diperhitungkan untuk memberi kesempatan anak bangsa mencapai posisi strategis daripada posisi sebagai buruh di negeri sendiri.
\end{abstract}

\section{Pendahuluan}

Akuntan adalah profesi yang dianggap sebagian pihak hanya berkutat pada masalah angka dan analisa untung rugi. Akuntan tidaklah sama dengan pekerjaan klerikal, bagian pembukuan dan "tukang catat". Namun akuntan memiliki peran yang besar dalam menyajikan informasi bagi para pembuat keputusan. Seperti definisi akuntansi menurut Accounting Principal Board (APB) No 4. Akuntansi adalah kegiatan jasa. Fungsinya adalah memberikan informasi kuantitatif, umumnya dalam ukuran uang, mengenai suatu badan ekonomi yang dimaksudkan untuk digunakan dalam pengambilan keputusan

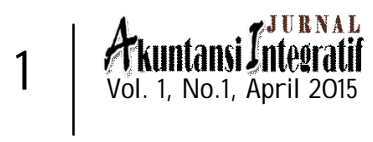


ekonomi sebagai dasar memilih diantara beberapa alternative ${ }^{1}$. Dari pengertian ini kita dapati bahwa di dalam akuntansi menyajikan informasi yang sangat berguna pagi para pembuat keputusan. Para pengambil keputusan (stakeholders) dapat berasal dari internal perusahaan seperti pihak manajemen atau karyawan, dapat pula dari pihak eksternal seperti pemerintah, kreditur, perbankan, Non Government Organization (NGO) dan lain sebagainya.

Informasi yang disajikan tentu saja harus relevan dan reliable. Dua factor tersebut adalah kualitas primer yang membuat informasi akuntansi berguna untuk pengambilan keputusan. Informasi yang relevanakan mampu membuat pemakai melakukan prediksi tentang hasil akhir kejadian masa lalu, kini dan masa yang akan datang. Sehingga dapat dikatakan relevan jika mempunyai nilai prediktif, nilai umpan balik dan ketepatan waktu. Sementara memiliki kualitas reliable jika dapat diverifikasi ( ditunjukkan jika menggunakan metode pengukuran yang sama akan mendapatkan hasil yang sama), disajikan secara tepat ( angka- angka yang disajikan mewakili apa yang benar ada dan terjadi), serta bebas dari kesalahan dan bias ( bersifat netral, informasinya bukan untuk kelompok tertentu, faktual dan benar). ${ }^{2}$

\section{Profesi Akuntan}

Kualitas informasi yang disajikan akan mencerminkan pengelolaan entitas secara transparan dan akuntabel, dan disinilah akuntan dituntut untuk dapat menjalankan profesinya secara professional. Seseorang yang telah menyelesaikan pendidikan setingkat strata satu biasanya sudah dapat disebut sebagai akuntan. Namun ada pula yang menuntut program pendidikan lanjutan untuk dapat menekuni spesialisasi tertentu di bidang akuntansi. Berikut berbagai profesi di bidang akuntansi:

\footnotetext{
${ }^{1}$ Sofyan Syafri H arahap, Teori Akuntansi (Jakarta: RajaG rafindo Persada, 2008), 5

${ }^{2}$ D onald E. Kieso dkk, Akuntansi Intermediate.terj. (Jakarta: Erlangga, 2008), 37-38
}

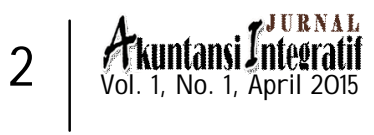


1. Akuntan Publik

2. Akuntan Manajemen

3. Auditor Pemerintah

4. Konsultan Pajak /Manajemen

5. Internal Auditor

6. Akuntan Pendidik

7. Keuangan Perusahaan

Adapun keahlian khusus di bidang akuntansi yang mengharuskan pendidikan lanjutan serta bersertifikasi Nasional dan internasional diantaranya:

1. CPA, Certified Public AccountantUntuk dapat memiliki sertifikat ini, seorang harus lulus Ujian Sertifikasi Akuntan Publik (USAP) dan terlebih dahulu haruslah memilkigelar akuntan. Penyandang gelar sertifikasi ini dapat membuka Kantor Akuntan Publik sendiri setelah memenuhi syarat yang ditentukan, termasuk syarat jam mengaudit.

2. CMA, Certified Management Accountantbagi Akuntan Manajemen, sertifikat ini sangat dikenal luas karena capabilitynya yang memiliki pemahaman menyeluruh terhadap akuntansi manajemen perusahaan.

3. QIA, Qualified Internal Auditor Qualified adalah sertifikasi profesi dalam bidang audit internal yang menunjukkan kualitas dan profesionalisme dari individu yang memilikinya. Sertifikat QIA juga merupakan pengakuan bahwa yang bersangkutan telah memiliki pengetahuan dan keterampilan yang sejajar dengan kualifikasi auditor internal tingkat internasional. ${ }^{3}$

4. SKP, Sertifikasi Konsultan Pajak adalah sertifikasi bagi individu yang memiliki kompetensi di bidang perpajakan. Sertifikasi ini diberikan oleh Ikatan Konsultan Pajak Indonesia (IKPI) ${ }^{4}$

5. CPSAK (Certified Pernyataan Standar Akuntansi Keuangan), sertifikasi yang menunjukkan keahlian di

${ }^{3}$ http://www.dsqia.com/standard-dan-pedoman-audit, 20 September 2015

${ }^{4}$ http://ikatankonsultanpajakindonesia.blogspot.co.id/p/uskp.html. 20 September 2015

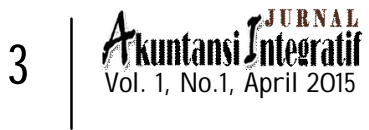


bidang penyusunan laporan keuangan sesuai dengan Pernyataan Standar Akuntansi Keuangan. ${ }^{5}$

6. CFE, Certified Fraud Examiners dikeluarkan olehAssociation of Certified Fraud Examiners (ACFE). Dengan memiliki sertifikat ini berarti seseorang memiliki pemahaman dan keahlian sebagai professional anti kecurangan. Syarat untuk mengikuti ujian CFE adalah minimum berpendidikan sarjana dan memiliki pengalaman kerja di bidang terkait (accounting $\mathcal{E}$ auditing, criminology $\mathcal{E}$ sociology, fraud investigation, loss prevention and law) minimum dua tahun.

7. SAS, Sertifikasi Akuntan Syariah adalah sertifikasi bagi individu yang memiliki kompetensi terhadap pemahaman ilmu akuntansi syariah.

8. AAP, Ahli Akuntansi Pemerintahan adalah sertifikasi yang diberikan untuk menunjukkan kompetensi individu dalam bidang akuntansi pemerintahan. ${ }^{6}$

Sedangkan gelar chartered accountant (CA) adalah akuntan teregister yang diakui internasional berdasarkan Mutual Recognition Agreement( MRA) sebagai implementasi untuk mempersiapkan era perdagangan bebas di tingkat Asia Tenggara. MRA memberikan pengakuan lisensi, register, untuk memudahkan perpindahan akuntan professional dari satu negara ke negara lain di ASEAN. MRA sendiri sebagai implementasi dari ASEAN Framework Agreement on Trade in Services (AFAS), yaitu kesepakatan di bidang jasa untuk diarahkan ke pasar bebas ASEAN. Seorang akuntan yang memiliki gelar CA dapat memberikan jasa konsultasi di bidang akuntansi, dia juga dapat membuka kantor jasa layanan akuntansi (KJA). Rencana berikutnya adalah dengan akan adanya RUU tentang Pelaporan Keuangan, maka pihak yang dapat membuat, menyajikan laporan keuangan hanyalah yang memilki sertifikat CA. Sehingga bagi akuntan yang telah

\footnotetext{
${ }^{5}$ http://www .iaiglobal.or.id/v02/berita/detail.php?catid = \&id $=142$

${ }^{6} \mathrm{http}: / / \mathrm{www}$. iaiglobal.or.id/v02/ppl/ppl.php?id=281, 20 September 2015
}

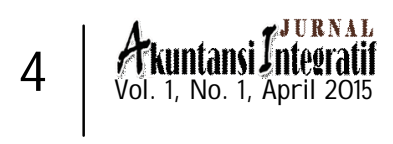


memiliki sertifikat CA akan menjadi nilai tambah bagi akuntan teregister.

Pemberian gelar CA sekaligus sebagai implementasi dari International Federation of Accountants dimana ada 7 (tujuh) Statements Membership Obligation (SMOs) yang harus dipatuhi oleh seluruh anggota IFAC sebagai berikut: yaitu quality, international education standards, auditing, IFAC code of ethics for professional accountants, public sector accounting standards, investigations and diciplines dan international financial reporting standards. Standar ini merupakan panduan global bagi seluruh stakeholders yang terkait untuk bersama-sama berinteraksi dalam membentuk seorang akuntan yang professional, dan IAI sebagai anggota IFAC harus secara konsisten melaksanakan action plan dalam rangka compliance program SMO IFAC ini.

\section{Masyarakat Ekonomi ASEAN (MEA)}

Masyarakat Ekonomi Asean (MEA) merupakan implementasi dari Declaration of ASEAN Concord II yang diselenggarakan pada 7 Oktober 2003 di Bali. Dengan MEA para pemimpin ASEAN menginginkan untuk mentrasformasikan ASEAN menjadi kawasan yang stabil, makmur dan berdaya saing tinggi dengan tingkat pembangunan yang merata serta kesenjangan sosial ekonomi dan kemiskinan yang semakin berkurang. MEA sesungguhnya wujud pasar bebas di ASEAN.

MEA akan membawa ASEAN memiliki empat karakteristik utama yaitu, sebagai pasar tunggal dan basis produksi, sebagai kawasan ekonomi yang berdaya saing tinggi, sebagai kawasan dengan pembangunan ekonomi yang merata dan sebagai kawasan yang terintegrasi penuh dengan ekonomi global. Dengan adanya kawasan terintegrasi akan memungkinkan satu Negara menjual barang dan jasa dengan mudah ke seluruh Asia Tenggara. Sebagai pasar tunggal tentu saja semua hambatan perdagangan baik tariff maupun non tariff akan dihilangkan. Tindak lanjut dari itu adanya ASEAN Framework

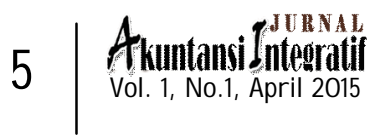


Agreement on Trade in Services (AFAS), yaitu kesepakatan di bidang jasa untuk diarahkan ke pasar bebas ASEAN. Adapun sector yang disepakati untuk diliberasi adalah jasa bisnis, jasa professional, konstruksi, distribusi, pendidikan, jasa lingkungan, pelayanan kesehatan, transportasi maritime, telekomunikasi dan turisme.

Bagaimana dengan kesiapan Indonesia menghadapi MEA? Perlu disiapkan karena hal ini akan berdampak pada beberapa konsekuensi logis yang tidak mungkin dihindari. Konsekuensi di bidang jasa adalah membanjirnya tenaga kerja asing yang akan masuk ke Indonesia. Sebagai bahan perbandingan kondisi profil tenaga kerja di Indonesia dengan Malaysia dan Singapura memperlihatkan bahwa hampir separuh tenaga kerja Indonesia adalah low skilled labour (dominasi lulusan sekolah dasar) sedangkan Singapura dan Malaysia $80 \%$ tenaga kerjanya adalah lulusan sekolah menengah dan perguruan tinggi.

Tabel prosentase Lulusan di tiga negara

\begin{tabular}{|l|l|l|l|l|l|}
\hline \multirow{2}{*}{ Lulusan } & \multicolumn{2}{|c|}{ Indonesia $^{7}$} & \multicolumn{2}{c|}{ Malaysia $^{8}$} & Singapura $^{9}$ \\
\cline { 2 - 6 } & Jml orang & persentase & Jml orang & persentase & Persentase \\
\hline SD & 52.000 .000 & $46,93 \%$ & & & \\
\hline SMP & 20.500 .000 & $18,5 \%$ & & & \\
\hline SMA & 17.840 .000 & $17,84 \%$ & 7.320 .000 & $55,79 \%$ & $49,9 \%$ \\
\hline SARJANA & 7.570 .000 & $6,83 \%$ & 3.190 .000 & $24,37 \%$ & $29,4 \%$ \\
\hline DIPLOMA & 2.920 .000 & $2,63 \%$ & & & \\
\hline TOTAL & 110.800 .000 & & & & \\
\hline
\end{tabular}

Tabel diatas semakin menegaskan posisi tidak berimbang antara Indonesia dengan Negara tetangga, sehingga bisa dikatakan belum siap sepenuhnya. Bagi Negara yang memiliki tenaga kerja dengan kualifikasi pendidikan dan kompetensi tinggi, MEA ini akan justru menjadi peluang untuk melakukan ekspansi tenaga kerja ke negara ASEAN lainnya.

\footnotetext{
${ }^{7}$ BPS agustus 2013

${ }^{8}$ Department of statistics malaysia 2012

${ }^{9}$ W orld bank 2012
} 
Salah satu target AFAS adalah menyediakan pengakuan akan pendidikan atau pengalaman, persyaratan, lisensi atau sertifikat yang disebut Mutual Recognition Arrangement (MRA). Dengan adanya pengakuan akan kualifikasi professional suatu profesi tertentu maka akan memudahkan perpindahan tenaga professional dari satu Negara ke Negara lainnya dalam kawasan ASEAN. Berikut bidang jasa yang telah ditandatangani Negara ASEAN:

1. Insinyur

2. Perawat

3. Framework Arrangement for Mutual Recognition on Surveying Qualification

4. Tourism professional

5. Accountancy Services

6. Medical Practitioners

7. Dental practitioners

8. Arsitek

Jika dilihat dari delapan bidang profesi yang telah ditandatangani, maka akuntan juga masuk dalam profesi yang ada keharusan sertifikat atau kualifikasi tertentu.

Ikatan Akuntan Indonesia adalah asosiasi profesi di bidang akuntansi yang menaungi sejumlah akuntan di Indonesia. Jumlah akuntan di Indonesia pada tahun 2013 sejumlah 17.649 akuntan masih kalah dengan Filipina, Singapura, Malaysia danThailand meskipun jumlah penduduk Indonesia lebih banyak dibandingkan Negara ASEAN lainnya. 
Tabel 1.2 Data Akuntan Publik dan Kantor Akuntan Publik

\begin{tabular}{|l|l|l|l|l|l|}
\hline No & Negara & Asosiasi & $\mathbf{2 0 0 8}$ & $\mathbf{2 0 1 0}$ & $\mathbf{2 0 1 3}$ \\
\hline 1 & Brunei & BICPA & 79 & 81 & 58 \\
\hline 2 & Cambodia & KICPAA & 799 & 256 & 284 \\
\hline 3 & Indonesia & IAI & 7.171 & 9.624 & 17.649 \\
\hline 4 & Lao PDR & LICPA & 166 & 172 & 176 \\
\hline 5 & Malaysia & MIA & 25.309 & 27.920 & 30.503 \\
\hline 6 & Phillipines & PICPA & 20.486 & 21.939 & 22.072 \\
\hline 7 & Singapore & ICPAS & 20.257 & 24.758 & 27.394 \\
\hline 8 & Thailand & FAP & 49.244 & 60.365 & 57.244 \\
\hline 9 & Vietnam & VAA & 7.500 & 8.000 & 8.000 \\
\hline 10 & Myanmar & MAC & 502 & 1.232 & 1.492 \\
\hline
\end{tabular}

Kebutuhan dunia kerja akan akuntan profesional sangat tinggi. Hingga awal tahun ini setidaknya ada 226.000 organisasi di Indonesia yang memerlukan jasa akuntan. ${ }^{10}$ Sementara, Pusat Pembinaan Akuntan dan Jasa Penilai (PPAJP) Kementerian Keuangan mencatat angkatan kerja yang tersedia kurang dari 16.000. Artinya, Indonesia masih kekurangan tenaga akuntan profesional11 Jika diasumsikan satu perusahaan membutuhkan setidaknya dua orang akuntan, maka akan dibutuhkan 452.000 akuntan pada tahun ini. Dari data ini saja sudah cukup jelas bahwa Indonesia masih membutuhkan jasa akuntan, bisa dibayangkan jika gap antara kebutuhan dan jumlah yang tersedia ini justru nantinya akan diisi oleh akuntan

10 http://www. iaiglobal.or.id/v02/berita/detail.php?catid\&id=617. Bersiap Diri Menyambut Pasar Tunggal ASEAN . Ikatan Akuntan Indonesia, 3 Februari 2014. 17 April 2015

11 http://ekbis.sindonews. com/read/877716/34/indonesia-kekurangan-akuntan-profesional1403869825. Diakses pada 27 Juni 2014 
dari luar ( mengingat jumlah akuntan dari negara ASEAN lebih banyak dibandingkan Indonesia sendiri).

Tabel. 1.3 Akuntan dan Kantor Akuntan Publik ${ }^{12}$

\begin{tabular}{|l|l|l|l|l|}
\hline Uraian & 2010 & 2011 & 2012 & 2013 \\
\hline Akuntan Beregister & 49.348 & 50.879 & 52.270 & 53.500 \\
\hline Akuntan Publik & 928 & 995 & 1.016 & 1.019 \\
\hline Kantor Akuntan Publik & 408 & 417 & 396 & 394 \\
\hline Cabang Kantor Akuntan Publik & 106 & 110 & 119 & 110 \\
\hline KAP yang bekerjasama dengan KAPA/OAA & 48 & 49 & 45 & 47 \\
\hline
\end{tabular}

\section{Menakar Kesiapan Indonesia :}

1. Secara kuantitas, Jumlah akuntan profesional di Indonesia relatif jauh lebih kecil dibandingkan Singapura, Malaysia, Thailand, dan Fillipina bahkan juga kalah dengan Vietnam. Kondisi masih kurangnya ketersediaan akuntan dibandingkan dengan yang tersedia, membuat kondisi "berbahaya" dalam artian Indonesia harus bersiap menghadapi serbuan akuntan asing.

2. Secara kualitas Indonesia masih dalam taraf membenahi sektor keprofesian. Hal ini terlihat dari upaya yang masih terus dilakukan Ikatan Akuntan Indonesia dengan melakukan pendataan ulang jumlah akuntan yang teregister dan berhak mendapatkan gelar CA (Chartered Accountant). Kemudian melakukan program pendidikan berkelanjutan, hal ini penting untuk memastikan bahwa

\footnotetext{
${ }^{12}$ Keliat,Makmur;Asra Virgianita; Shofwan Al Banna; Agus Catur Aryanto. Pemetaan Pekerja Terampil Indonesia dan Liberalisasi Jasa ASEAN. Laporan Penelitian ASEAN Study Center III, 2013
}

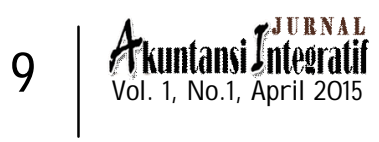


akuntan yang ada tidak hanya "gelar" tetapi juga memiliki kualifikasi yang diharapkan.

3. Kemampuan Bahasa asing. Terbukanya arus barang dan jasa yang diikuti dengan bebasnya keluar masuk tenaga atau sumber dayanya akan membuat kebutuhan komunikasi menggunakan bahasa asing menjadi satu hal yang penting. Jika melihat upaya Negara tetangga yang sudah membuka kelas belajar bahasa Indonesia, menunjukkan keseriusan mereka untuk masuk ke dalam pasar jasa Indonesia. Namun kita dapati masih banyak lulusan perguruan tinggi kita yang tidak memiliki kemampuan bahasa asing cukup baik. Tentu hal ini akan menjadi kendala di saat pasar bebas itu dibuka.

\section{Kebutuhan Saat Ini}

a. Upgrade akuntan dengan kompetensi

IAI melalui Dewan Pengurus Nasional telah mengelurkan surat keputusan tentang kewajiban memelihara dan meningkatkan kompetensi melalui kegiatan pendidikan professional berkelanjutan (PPL) bagi anggota utama IAI atau Chartered Accountant. Pendidikan professional berkelanjutan adalah kegiatan belajar terus menerus (continuous learning) yang harus ditempuh oleh akuntan professional agar senantiasa dapat memelihara, meningkatkan dan mengembangkan kompetensi professionalnya.

Kegiatan ini bertujuan agar akuntan professional dapat memelihara, meningkatkan dan mengembangkan kompetensi profesionalnya secara berkesinambungan, membekali akuntan dengan pengetahuan mutakhir dibidangnya dan menjaga serta meningkatkan kepercayaan masyarakat kepada profesi akuntan. ${ }^{13}$

13 Surat Keputusan Dewan Pengurus nasional Ikatan Akuntan Indonesia No. KEP38/SK/D PN /IAI/X II/2012, Psl 1 
b. Menjaring calon akuntan (akuntan muda).

Banyaknya lulusan jurusan akuntansi yang tidak berprofesi menjadi akuntan, menjadi tantangan tersendiri. Apalagi saat ini terdapat kesenjangan antara jumlah akuntan yang tersedia dengan jumlah akuntan yang dibutuhkan. Untuk itu harus ada upaya sejak dini untuk menjaring calon akuntan dengan melibatkan mereka dalam kegiatankegiatan profesinya kelak. Dengan mendekatkan dan melibatkan mereka pada dunia profesinya, diharapkan lulusan akuntansi juga akan dapat berkiprah sesuai dengan profesinya dan dapat memiliki kompetensi dan keahlian lebih lebih awal.

c. Pembenahan Kurikulum

Dengan diterapkannya pasar bebas di kawasan ASEAN menuntut adanya materi yang sifatnya internasional. Terdapat beberapa masalah seperti ketidakseragaman kompetensi lulusan akuntansi di Indonesia diakibatkan beragamnya beban satuan kredit semester (SKS), problem dari sisi pendidik yang belum memiliki kualifikasi akademik, belum pernah mengikuti training of trainers (TOT). sehingga perlu pembenahan untuk menghapus talent gap menghadapi Masyarakat Ekonomi Asean. ${ }^{14}$

d. Perbaikan Program Profesi Berkelanjutan

Sertifikasi CA adalah akuntan yang memiliki kompetensi mencakup tujuh aspek, yaitu; 1) Pelaporan Korporat, 2) Manajemen Stratejik dan Kepemimpinan, 3) Tata Kelola Korporat dan Etika, 4) Akuntansi Manajemen Lanjutan, 5) Manajemen Perpajakan, 6) Manajemen Keuangan Lanjutan, dan 7) Sistem Informasi dan Pengendalian Internal.

Program sertifikasi yang telah berjalan selama ini baru pada taraf memastikan jumlah perolehan SKP sejumlah tertentu, namun tidak memastikan kompetensi apa saja yang harus dimiliki selama jangka waktu tertentu. Idealnya

\footnotetext{
${ }^{14}$ Basri Musri, Siapkah Akuntan Pajak Indonesia M enghadapi M ea? Dalam Akuntan Indonesia. Edisi Agustus September 2015
}

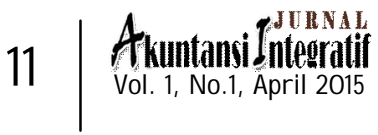


Ikatan Akuntan Indonesia (IAI) akan memberikan sertifikat CA bagi akuntan yang telah memiliki tujuh kompetensi tersebut. Melalui serangkaian sosialisasi, upgrading (program profesi berkelanjutan) untuk selanjutnya sertifikat ini memiliki masa durasi tertentu misalnya tiga tahun. Artinya setelah tiga tahun maka akan ada kewajiban untuk melakukan upgrading kembali akan kompetensi yang dimilikinya.

Selain itu juga selayaknya memberi kemudahan akan biaya dan tempat yang terjangkau, agar program profesi berkelanjutan dapat dilaksanakan kapan saja, dimana saja tanpa terkendala biaya dan tempat. Mengingat selama ini program profesi berkelanjutan hanya tersedia rutin di IAI Pusat tetapi tidak demikian di daerah, demikian pula dengan besarnya biaya yang relatif mahal dan ada keharusan untuk mengumpulkan 30 SKP setiap tahunnya, sehingga tidak dapat dipastikan apakah program yang diikuti seorang akuntan benar benar sesuai yang diharapkan atau sekedar mengumpulkan SKPsaja.

e. Berhitung Ulang Kesiapan Menuju MEA

Melihat kondisi sumber daya di Indonesia yang masih tertinggal dengan Negara tetangga, kiranya perlu untuk ditinjau ulang klaim kesiapan Indonesia menuju MEA. Sebab masih besarnya kebutuhan akuntan di Indonesia dan itupun belum terpenuhi dari negeri sendiri maka harus siap untuk mendapat serbuan tenaga akuntan dari luar. Jika hal ini terjadi maka peluang tenaga kerja justru akhirnya banyak diisi oleh tenaga asing dibandingkan dari bangsa sendiri. Posisi strategis atau middle up justru diisi dari asing sementara bangsa sendiri justru mengisi posisi sebagai buruh. Hal ini baru melihat dari sisi profesi akuntan, belum dari keenam profesi lainnya.

\section{Kesimpulan}

Posisi akuntan menjelang era keterbukaan lalu lintas jasa di satu sisi cukup menggembirakan dengan adanya sertifikasi

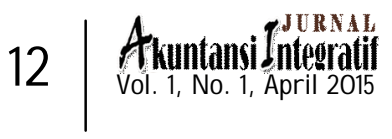


yang mengakui profesi ini di kawasan ASEAN. Namun disisi lain ada banyak hal yang harus dibenahi yaitu jumlah akuntan yang masih kurang dibandingkan dengan jumlah yang dibutuhkan, kondisi Asosiasi yang masih terus melakukan pembenahan dan upgrading terhadap anggotanya, serta pemberlakuan Masyarakat Ekonomi ASEAN yang tinggal selangkah lagi sementara kualitas sumber daya di Indonesia di dominasi low skilled labour menjadi kondisi yang bisa dikatakan "berbahaya" karena rentan serbuan tenaga asing bahkan bukan hal yang mustahil nantinya akan didapati bahwa kita akan menjadi bangsa buruh di negeri sendiri.

\section{Daftar Pustaka}

Sofyan Syafri Harahap, Teori Akuntansi. Jakarta: RajaGrafindo Persada, 2008.

Donald E. Kieso dkk, Akuntansi Intermediate.terj. Jakarta: Erlangga, 2008.

BPS agustus 2013

Department of statistics malaysia 2012

World bank 2012

http://ekbis.sindonews.com/read/877716/34/indonesia-

kekurangan-akuntan-profesional-1403869825. Diakses pada 27 Juni 2014

Surat Keputusan Dewan Pengurus nasional Ikatan Akuntan

Indonesia No. KEP-38/SK/DPN/AAI/XII/2012, Psl 1

http:/wwww.dsqia.com/standard-dan-pedoman-audit,

September 2015

http://katankonsultanpajakindonesia.blogspot.co.id/p/uskp.ht

ml. 20 September 2015

http://www.iaiglobal.or.id/v02 berita/detail.php?catid=\&id=142

http:/www.iaiglobal.or.id/v02/ppl/ppl.php?id=281,

September 2015

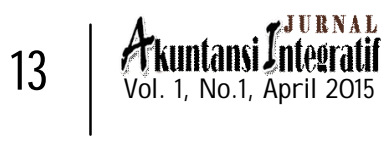


Vidia Gati

http:/www.iaiglobal.or.id / 02 berita/detail.php?catid\&id=617. Bersiap Diri Menyambut Pasar Tunggal ASEAN. Ikatan Akuntan Indonesia, 3 Februari 2014. 17 April 2015 